\title{
Cost-utility of denosumab for the treatment of postmenopausal osteoporosis in Spain
}

This article was published in the following Dove Press journal:

ClinicoEconomics and Outcomes Research

9 February 2015

Number of times this article has been viewed

Josep Darbà'

Lisette Kaskens ${ }^{2}$

Francesc Sorio Vilela ${ }^{3}$

Mickael Lothgren ${ }^{4}$

'Department of Economics, Universitat de Barcelona, ${ }^{2} \mathrm{BCN}$

Health Economics and Outcomes

Research SL, ${ }^{3}$ Amgen SA, Barcelona, Spain; ${ }^{4}$ Amgen (Europe) $\mathrm{GmbH}$, Zug,

Switzerland
Correspondence: Josep Darbà

Department of Economics, Universitat

de Barcelona, Diagonal 690,

Barcelona 08034, Spain

Tel +3493402 1937

Email darba@ub.edu
Background: The objective of this study was to estimate the cost-effectiveness of denosumab for fracture prevention compared with no treatment, generic bisphosphonates, and strontium ranelate in a cohort of osteoporotic postmenopausal women in Spain.

Methods: A Markov model represented the possible health state transitions of Spanish postmenopausal women from initiation of fracture prevention treatment until age 100 years or death. The perspective was that of the Spanish National Health System. Fracture efficacy data for denosumab were taken from a randomized controlled trial. Fracture efficacy data for alendronate, ibandronate, risedronate, and strontium ranelate were taken from an independent meta-analysis. Data on the incidence of fractures in Spain were either taken from the published literature or derived from Swedish data after applying a correction factor based on the reported incidence from each country. Resource use in each health state was obtained from the literature, or where no data had been published, conservative assumptions were made. Utility values for the various fracture health states were taken from published sources. The primary endpoints of the model were life-years gained, quality-adjusted life-years (QALYs), and incremental costeffectiveness ratios for denosumab against the comparators.

Results: Denosumab reduced the risk of fractures compared with either no treatment or the other active interventions, and produced the greatest gains in life-years and QALYs. With an annual acquisition cost of $€ 417.34$ for denosumab, the incremental cost-effectiveness ratios for denosumab versus no treatment, alendronate, risedronate, and ibandronate were estimated at $€ 6,823$, $€ 16,294, € 4,895$, and $€ 2,205$ per QALY gained, respectively. Denosumab dominated strontium ranelate. Sensitivity analyses confirmed the robustness of these findings.

Conclusion: Our analyses show that denosumab is a cost-effective intervention for fracture prevention in osteoporotic postmenopausal women in Spain compared with alendronate and risedronate, and is a dominant treatment option compared with strontium ranelate.

Keywords: osteoporosis, post-menopausal, cost-utility, denosumab, Spain

\section{Introduction}

Osteoporosis is a progressive skeletal disease that commonly occurs in women as they age, leading to a reduction in bone mass and quality, ${ }^{1-3}$ and ultimately increased susceptibility to bone fractures. It is a disorder associated with significant fracture-related morbidity in elderly postmenopausal women, including negative effects on quality of life because of chronic pain, depression, and limitations on social activity, ${ }^{4-7}$ as well as increased mortality. ${ }^{8}$ Estrogen deficiency is one of the main determinants of osteoporosis in women after menopause. ${ }^{9}$ Epidemiology data from Spain suggest a prevalence rate of postmenopausal osteoporosis (PMO) of approximately 25\% for women aged 60-69 years and $40 \%$ for those aged $70-79$ years. ${ }^{10}$ As such, PMO places a significant burden on 
health care resources, particularly owing to the increased risk of fractures. ${ }^{11-13}$ In 2009, it was estimated that the costs of osteoporosis in Europe would double from $€ 40$ billion in 2000 to almost $€ 80$ billion in $2050 .{ }^{14}$ The cost related to hospitalizations due to osteoporotic vertebral fractures in Spain was estimated to be $€ 41$ million in $2007 .{ }^{15}$ A more recent estimate for osteoporotic hip fractures in Catalonia put the direct costs in this region alone at $€ 50$ million. ${ }^{16}$

Pharmacological treatment options for PMO can generally be classified by their action on bone remodeling as either antiresorptive or anabolic agents, with the primary goal of treatment being a reduction in fracture risk. ${ }^{17}$ Antiresorptive drugs generally act to reduce bone remodeling, and lower fracture risk by preserving the microarchitecture of the skeleton and increasing bone mass. ${ }^{18}$ Antiresorptive drugs such as bisphosphonates are established therapies for PMO. ${ }^{8,12,19}$ Denosumab is a relatively new antiresorptive agent that targets the cytokine system involved in bone turnover regulation (RANKL, a cytokine that is an essential mediator for osteoclast formation, function, and survival). ${ }^{20}$ Denosumab is a human monoclonal antibody with high affinity and specificity for RANKL. ${ }^{21}$ By binding to and inhibiting RANKL, denosumab prevents its interaction with its receptor, RANK, on osteoclasts and their precursors, thus inhibiting bone resorption. Anabolic treatments, such as teriparatide, have been used more recently to stimulate bone formation. ${ }^{11,18,20,22}$ In addition, drugs such as strontium ranelate, which work by inhibiting the osteoclast and stimulating the osteoblast, have been approved for the treatment of PMO in Europe over the last few years..$^{20,23}$

Oral bisphosphonates are well established as effective first-line therapies for the management of PMO. However, some forms of bisphosphonate therapy can involve potentially inconvenient dosing regimens, including daily/ weekly administration, which may have implications for adherence. ${ }^{8,24-28}$ They may also have adverse effects, such as gastrointestinal irritation ${ }^{29}$ or nephrotoxicity. ${ }^{30,31}$ These and other well-known potential adverse effects may limit bisphosphonate use in some women with PMO. Moreover, consideration of these adverse events and lack of adherence may influence their overall cost-effectiveness relative to other guideline-recommended PMO treatments. The Spanish treatment guidelines, issued by the Spanish Society of Rheumatology, have recently been updated to reflect new developments in the management of PMO, and include two new antiresorptive drugs, bazedoxifene and denosumab. ${ }^{32}$ However, there is a lack of information comparing the costeffectiveness of these newly recommended treatments with relevant alternative options that would help better inform clinical decision-making in Spain.

The objective of this study was to estimate the costeffectiveness of denosumab for osteoporotic fracture prevention compared with generic bisphosphonates (alendronate, ibandronate, risedronate), strontium ranelate, and no treatment in a cohort of postmenopausal Spanish women.

\section{Patients and methods Model structure}

A Markov model (Figure 1) was created to represent the possible health state transitions of Spanish postmenopausal women from initiation of treatment for fracture prevention until age 100 years or death. The model was developed from a previously published model used to assess the cost-effectiveness of denosumab for the treatment of PMO in different countries. ${ }^{33}$ The current analyses were conducted from the perspective of the Spanish National Health System.

The model covered a total of eight health states: "well", "wrist fracture", "vertebral fracture", "hip fracture", "other osteoporotic fracture", "post-vertebral fracture", "post-hip fracture", and "dead". The cycle length for transition between the various health states was 6 months. All patients began in the "well" health state. In each cycle, patients could experience a fracture, remain healthy, or die, and could transition between health states.

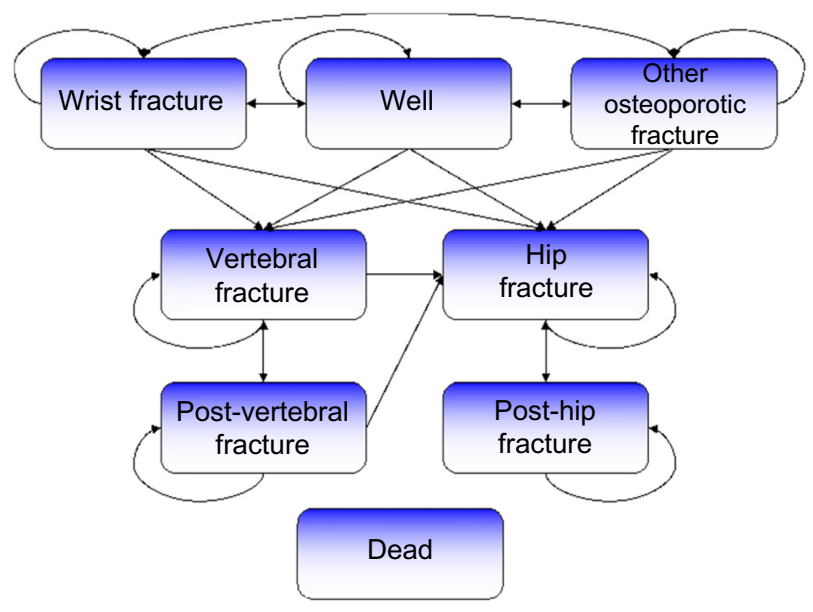

Figure I Markov model used to represent the possible health state transitions of Spanish women with postmenopausal osteoporosis.

Notes: The analysis time began from the initiation of fracture prevention treatment until age 100 years or death. This model was developed from Jonssen et $\mathrm{al}^{33}$ with the analyses conducted from the perspective of the Spanish National Health Service. Springer and the original publisher, Osteoporosis International, volume 22, 2010, page 968, Cost-effectiveness of Denosumab for the treatment of postmenopausal osteoporosis, B. Jönsson, O. Ström, J. A. Eisman, A. Papaioannou, E. S. Siris, A. Tosteson, I. A. Kanis, figure I. (C) International Osteoporosis Foundation and National Osteoporosis Foundation 2010. With kind permission from Springer Science and Business Media. 
If the patient died, they moved to the "dead" health state and remained there for the rest of the simulation. If the patient incurred a fracture, they moved, depending on fracture type, to either the "hip fracture", "vertebral fracture", "wrist fracture", or "other osteoporotic fracture" health states. After 1 year in one of these health states, the patient could experience a new fracture, or move to the "post-hip fracture", "post-vertebral fracture", or "dead" health states. Those with wrist fractures and other osteoporotic fractures were assumed to have had an impact on costs and morbidity in the first year after the fracture only, and therefore, after 1 year in these health states, these patients moved (assuming no new fracture had occurred) back to the "well" health state.

Patients in the post-vertebral fracture state could stay in this state, have a vertebral fracture or hip fracture, or die. Those in the "post-hip fracture" health state could only stay in this health state, have another hip fracture, or die. Consequently, patients who had a hip fracture could not experience any future wrist, vertebral, or other osteoporotic fractures, and patients in the vertebral and post-vertebral health states could not have a wrist fracture, which highlights a limitation of the model. Patients who sustained fractures incurred fracture-specific costs and reductions in health utilities.

The risk of sustaining a fracture in the model depends on three elements: the risk for an individual in the general population of incurring a fracture (specific input by age and fracture location based on epidemiology data); the increased fracture risk associated with osteoporosis (relative risk [RR]); and a risk reduction, if any, attributed to a treatment.

The RR of fracture in patient groups compared with the general population risk was calculated from age, bone mineral density (BMD), and the prevalence of vertebral fractures using previously described methods. ${ }^{34-36}$ The risk contribution from prior vertebral fracture was re-estimated for each cycle to account for age-dependent changes in the prevalence of vertebral fracture in the general population. The RR of hip fractures was also adjusted over time to accommodate the decreasing gradient of fracture risk per standard deviation of BMD with age. ${ }^{37}$ RRs at or below a certain femoral neck T-score were calculated by dividing the distribution below a given T-score into 0.1 standard deviation wide slices, and summarizing the RR. This method was applied because RR increases exponentially with decreasing BMD.

Note that the model estimates consequences of vertebral fractures that come to clinical attention whilst the baseline risk of the patient population also is based on the prevalence of morphometric fractures. This method was used conserva- tively because morphometric vertebral fractures contribute to fracture risk, ${ }^{38}$ but have unclear consequences for costs and quality of life. ${ }^{33}$

\section{Efficacy and safety}

The fracture efficacy data for denosumab were derived from FREEDOM (Fracture REduction Evaluation with Denosumab in Osteoporosis every 6 Months), the pivotal trial that constituted the basis for approval of denosumab in the USA and European Union. ${ }^{39,40}$ The FREEDOM trial consisted of 7,868 women with a mean age of 72 years. The mean BMD T-scores were -2.8 at the lumbar spine, -1.9 at the total hip, and -2.2 at the femoral neck. Approximately one quarter (24\%) of the women had a vertebral fracture at baseline. Denosumab reduced the fracture risk by $68 \%$ (95\% confidence interval [CI] 59-74), 40\% (95\% CI 3-63), 20\% (95\% CI 5-33), and $16 \%(95 \%$ CI $-11,37)$ for new vertebral, hip, non-vertebral, and wrist fractures, respectively. ${ }^{39,40}$ The risk reductions for non-vertebral fractures were used as the efficacy values for "other" fractures.

The efficacy data for the other active treatment comparators were taken from a meta-analysis conducted by the National Institute for Health and Care Excellence. ${ }^{41}$ The efficacy rates for all the comparators included can be seen in Table 1.

The FREEDOM study also included prespecified subgroup analyses of patients at higher risk of fracture, including those with a baseline femoral neck BMD T-score -2.5 or less. ${ }^{39,42,43}$ We used the efficacy data in this subpopulation of high-risk patients in FREEDOM for sensitivity analyses. As no other product had reported data in a similar subpopulation, a conservative approach was taken by not varying the efficacy rates for the comparators in sensitivity analyses. For the multivariate sensitivity analysis, specific efficacy data for denosumab were used for patients older than 75 years. This was not done for comparators, again following a conservative approach, since risk reductions for this specific population were either not reported or lower than that in the overall population (Table 1).

Adverse events associated with osteoporosis medications, including denosumab, are usually mild and transient. ${ }^{40,44,45}$ The cost and quality of life impact of adverse events would be minor and they were not included in the analysis as in other studies. ${ }^{46}$

\section{Fracture incidence and mortality}

Data on the incidence of fractures in Spain were taken from either the published literature (in the case of hip fractures) $)^{47}$ 


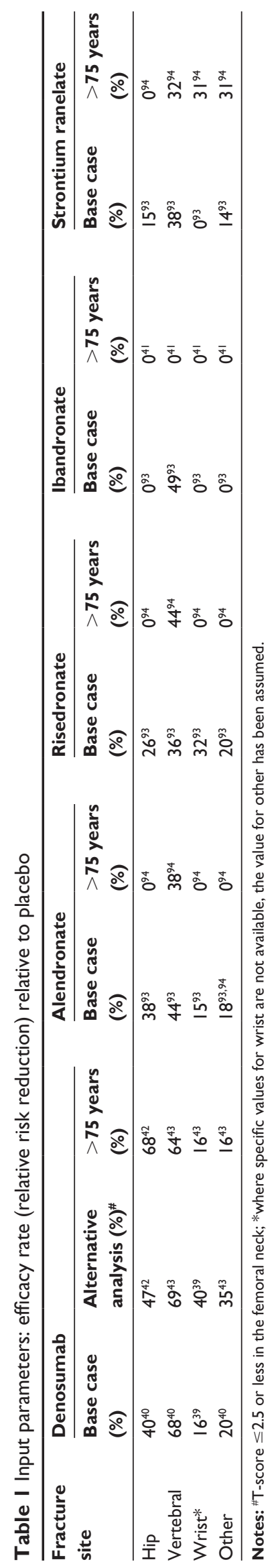

or derived from Swedish data after applying a reduction factor based on the reported incidence from both countries (Spain compared with Sweden) ${ }^{48-51}$ These were then linearly extrapolated and interpolated with the midpoint values for a range of ages used (eg, age 52 years in the 50-54-year age group). Patients with hip or vertebral fractures have an increased mortality risk compared with the general population. $^{52,53}$ Wrist fractures are not associated with increased mortality at any age. Increased mortality risks due to hip or vertebral fracture were applied, from published sources, ${ }^{52,53}$ to the Spanish mortality rate for women based on 2009 data. ${ }^{54}$ The RR of death, in the case of hip and vertebral fractures, declines with age, and this was factored into the model. A study on the RR of death from "other fractures" showed that the variation in fracture risk did not vary greatly by age,, 5 so the RR of death remained as a constant for all ages in our model. Evidence suggests that much of the excess mortality associated with osteoporosis is not actually a function of the fracture, ${ }^{53,56}$ but perhaps of the generally more frail condition of patients with osteoporosis. As such, the RRs of death after fracture were adjusted for comorbidities, and the duration of the increased mortality used in the model was 8 years, which was the follow-up period of the two studies used here to estimate comorbidity. ${ }^{48,51}$

The population incidence and risk of fractures by type and age, and the RR of mortality linked to the different fracture types and age, can be seen in Table 2 . The RRs resulting from the model for sustaining a fracture at the hip, spine, wrist, or "other sites" for the base-case population (T-score $\leq 2.5$ or less, started treatment at age 65 years, and $28 \%$ prevalence of osteoporotic fracture) compared with the overall population were $4.36,3.20,1.68$, and 2.00 , respectively. This confirms the higher risk of fracture of the base-case population compared with the overall population.

\section{Resource use and costs}

Resource use and resource unit cost were collected separately. The resource use in each health state was obtained from the literature where possible, and, for those where no data had been published, conservative assumptions were made as to the probable level of resource consumption. Data obtained from the literature included hospital admissions, nursing home costs, and drug treatments for osteoporosis. The costs of resources used were taken from published sources, individual hospitals, or nationally available data sources such as eSalud ${ }^{57}$ and BOT Plus (Portalfarma, Consejo Oficial de Colegios Oficiales de Farmacéuticos), ${ }^{58}$ and were inflated to 2013 prices using the Spanish Consumer Price Index 
Table 2 Fracture incidence and mortality at selected ages

\begin{tabular}{|c|c|c|c|c|c|c|c|c|c|}
\hline \multirow{2}{*}{$\begin{array}{l}\text { Age } \\
\text { (years) }\end{array}$} & \multicolumn{5}{|c|}{ Risk of fracture } & \multicolumn{4}{|c|}{ Risk of mortality compared with population norms } \\
\hline & Hip & Vertebral & Wrist & Other & $\begin{array}{l}\text { Hip } \\
\text { (year I) }\end{array}$ & $\begin{array}{l}\text { Vertebral } \\
\text { (year I) }\end{array}$ & $\begin{array}{l}\text { Hip } \\
\text { (year 2+) }\end{array}$ & $\begin{array}{l}\text { Vertebral } \\
\text { (year 2+) }\end{array}$ & $\begin{array}{l}\text { Other } \\
\text { (year I) }\end{array}$ \\
\hline 50 & 0.00025 & 0.00124 & 0.00225 & 0.00304 & 9.79 & 12.07 & 3.62 & 7.94 & 1.22 \\
\hline 55 & 0.00023 & 0.00121 & 0.00247 & 0.00370 & 8.64 & 10.15 & 3.34 & 6.67 & 1.22 \\
\hline 60 & 0.00054 & 0.00187 & 0.00293 & 0.00392 & 7.69 & 9.04 & 3.11 & 5.94 & 1.22 \\
\hline 65 & 0.00104 & 0.00293 & 0.00359 & 0.00663 & 6.39 & 7.43 & 2.70 & 4.88 & 1.22 \\
\hline 70 & 0.00221 & 0.00490 & 0.00459 & 0.00948 & 5.54 & 5.98 & 2.44 & 3.93 & 1.22 \\
\hline 75 & 0.00496 & 0.00745 & 0.00549 & 0.01553 & 4.16 & 4.39 & 1.91 & 2.88 & 1.22 \\
\hline 80 & 0.00996 & 0.00870 & 0.00637 & 0.02268 & 2.92 & 2.75 & 1.39 & 1.81 & 1.22 \\
\hline 85 & 0.01817 & 0.01105 & 0.00737 & 0.03800 & 2.15 & 1.98 & 1.06 & 1.30 & 1.22 \\
\hline 90 & 0.02543 & 0.01469 & 0.00837 & 0.05955 & 1.63 & 1.36 & 1.00 & 1.00 & 1.22 \\
\hline
\end{tabular}

where appropriate (not for drug costs). Certain assumptions were also made in the absence of published information: all interventions were associated with a single physician visit per year, as part of the standard monitoring of treatment. In addition, denosumab was associated with the cost of one nurse visit per year due to its 6-month subcutaneous injection cycle (assuming that $50 \%$ of all doses in a year were either self-administered, administered by a relative, or administered during annual physician visits) and there were no differences in tests or analyses due to the treatment administered.

In the base-case analysis, it was assumed that only hip fractures would potentially incur long-term care costs (associated with residence in nursing homes). The probability of requiring a nursing home was conservatively assumed to be $15 \%$ based on two previously published Spanish studies. ${ }^{59,60}$

The other types of fractures (wrist, vertebral, and others) were associated only with costs at the time of the event. Both costs and benefits were discounted at 3\% in the base case in line with current best practice in Spain. ${ }^{61}$ The costs included in the analyses are reported in Table 3. The retail price of denosumab and the comparator treatments were used, including a mandatory $7.5 \%$ reduction in the cases of strontium ranelate and denosumab, as mandated for branded drugs in Spain. ${ }^{58}$

\section{Utilities}

Utility values, which represent the reduction in quality of life, for the various fracture health states were taken from published sources..$^{62,63}$ The five-dimension European quality of life questionnaire values for the general population in Spain were taken from a recent publication..$^{38}$ These values are shown in Table 4. It was assumed that only hip and vertebral fractures would have associated disutility beyond the first year post-fracture.

\section{Persistence}

Several economic analyses previously undertaken have failed to consider persistence with treatment, which reduces their usefulness to decision-makers. ${ }^{64}$ The presented model analyses explicitly included treatment persistence and its impact on predicted treatment costs and health outcomes. In the model, persistence was defined as the length of time that the medication was taken by the patient. Persistence rates for denosumab treatment were based on the DAPS (Denosumab Adherence Preference Satisfaction) study, ${ }^{62}$ a randomized crossover study

Table 3 Costs (2013 prices)

\begin{tabular}{|c|c|c|c|c|}
\hline & \multicolumn{4}{|c|}{ Cost (€) } \\
\hline & \multicolumn{4}{|c|}{ Age group (years) } \\
\hline & $50-64$ & $65-74$ & $75-84$ & $\geq 85$ \\
\hline \multicolumn{5}{|l|}{ Fracture site ${ }^{95}$} \\
\hline Hip & 10,236 & | I,93| & 12,684 & $|8,84|$ \\
\hline Vertebral & 3,994 & 13,683 & 13,683 & 13,683 \\
\hline Wrist & $|, 98|$ & I,98| & I,98| & $|, 98|$ \\
\hline Other & $\mathrm{I}, 98 \mathrm{I}$ & $\mathrm{I}, 98 \mathrm{I}$ & $|, 98|$ & $\mathrm{I}, 98 \mathrm{I}$ \\
\hline $\begin{array}{l}\text { Annual drug costs } \\
\text { (including all sales taxes) }^{58}\end{array}$ & \multicolumn{4}{|c|}{ Cost $(€)$} \\
\hline Denosumab & \multicolumn{4}{|l|}{417.34} \\
\hline Alendronate & \multicolumn{4}{|l|}{162.82} \\
\hline Risedronate & \multicolumn{4}{|l|}{283.80} \\
\hline Ibandronate & \multicolumn{4}{|l|}{156.00} \\
\hline Strontium ranelate & \multicolumn{4}{|l|}{595.54} \\
\hline \multicolumn{5}{|l|}{ Non-drug costs } \\
\hline $\begin{array}{l}\text { Medical costs associated } \\
\text { with hip fracture (year } 2+)^{95}\end{array}$ & \multicolumn{4}{|l|}{5,480} \\
\hline $\begin{array}{l}\text { Daily cost of nursing home/ } \\
\text { long-term care }{ }^{57}\end{array}$ & \multicolumn{4}{|l|}{86.95} \\
\hline Cost of a physician visit ${ }^{95}$ & \multicolumn{4}{|l|}{59.18} \\
\hline $\begin{array}{l}\text { Cost of IV administration } \\
\text { per injection }{ }^{57}\end{array}$ & \multicolumn{4}{|l|}{209.33} \\
\hline Cost of a nurse visit ${ }^{57}$ & \multicolumn{4}{|l|}{20.67} \\
\hline
\end{tabular}

Abbreviation: IV, intravenous. 
Table 4 Utility values and treatment persistence

\begin{tabular}{|c|c|c|}
\hline Fracture & \multicolumn{2}{|c|}{ Utility multiplier } \\
\hline \multicolumn{3}{|l|}{ First year only } \\
\hline Hip & \multicolumn{2}{|l|}{0.700} \\
\hline Vertebral & \multicolumn{2}{|l|}{0.590} \\
\hline Wrist & \multicolumn{2}{|l|}{0.956} \\
\hline Other & \multicolumn{2}{|l|}{0.902} \\
\hline \multicolumn{3}{|l|}{ Subsequent years } \\
\hline Hip & \multicolumn{2}{|l|}{0.800} \\
\hline Vertebral & \multicolumn{2}{|l|}{0.929} \\
\hline \multirow{2}{*}{$\begin{array}{l}\text { Time since } \\
\text { initiation (months) }\end{array}$} & \multicolumn{2}{|c|}{ Discontinuation rates (\%) } \\
\hline & Denosumab & Comparators \\
\hline \multicolumn{3}{|l|}{ Persistence rates } \\
\hline 6 & 18.6 & 37.2 \\
\hline 12 & 13.1 & 26.1 \\
\hline 18 & 11.2 & 22.4 \\
\hline 24 & 9.9 & 19.8 \\
\hline 30 & 10.2 & 20.5 \\
\hline 36 & 15.2 & 30.3 \\
\hline Age (years) & \multicolumn{2}{|l|}{ Mean } \\
\hline \multicolumn{3}{|c|}{ EQ-5D mean index values (time trade-off value set) } \\
\hline $18-24$ & \multicolumn{2}{|c|}{0.981} \\
\hline $25-34$ & \multicolumn{2}{|l|}{0.970} \\
\hline $35-44$ & \multicolumn{2}{|l|}{0.942} \\
\hline $45-54$ & \multicolumn{2}{|l|}{0.919} \\
\hline $55-64$ & \multicolumn{2}{|l|}{0.894} \\
\hline $65-74$ & \multicolumn{2}{|l|}{0.857} \\
\hline$\geq 75$ & \multicolumn{2}{|l|}{0.729} \\
\hline Total & \multicolumn{2}{|l|}{0.912} \\
\hline
\end{tabular}

Abbreviation: EQ-5D, five-dimension European quality of life questionnaire.

that compared the persistence on denosumab with that of weekly alendronate in a cohort of 250 patients observed for 24 months. This study showed that non-persistence in the first year (before crossover) was $9.5 \%$ for denosumab and $20.2 \%$ for alendronate, which represents a $50 \% \mathrm{RR}$ reduction in non-persistence with denosumab. ${ }^{65}$ Persistence rates for the bisphosphonates and strontium ranelate were taken from the Swedish Adherence Register Analysis study, which included data on over 56,000 patients treated for osteoporosis between 2005 and 2009. ${ }^{66}$ For the comparators, a composite estimate was used rather than the persistence rates for individual treatments because it was felt that comparator persistence would appear to be too low as many patients may simply have switched to an alternative treatment. Persistence for denosumab was obtained applying the RR reduction obtained in DAPS to the composite estimate for comparators. The persistence rates used in the model are also presented in Table 4.

In the base-case population, it was assumed that patients were at risk of discontinuing treatment during the first 3 years only, after which they would remain adherent to their treatment until termination or death.
It has been recognized that treatment effects in osteoporosis persist for a length of time even after the treatment has stopped (defined as the offset time), ${ }^{67,68}$ and that this can impact cost-effectiveness. ${ }^{69-72}$ There have been very few studies that evaluate offset time. The findings also seem inconsistent. For all treatments, the offset time could not be determined precisely for fractures. When making assumptions for an economic model, differential effects for treatments should be based on solid evidence. At this time, there is not robust evidence to support differential offsets, so we assume that they are equal for all treatments. In the absence of more conclusive evidence for differential offset time, the offset time used in the base-case analysis was assumed to be equivalent to the time spent on treatment up to a maximum of 2 years; this was shorter for patients who discontinued treatment earlier. Additionally, the treatment effect decreased linearly during the offset time. The model assumed that the maximum duration of treatment for a fully persistent patient would be 5 years; therefore, the maximum treatment effect time would be 7 years (comprising 5 years of full persistence and 2 years of offset time).

\section{Analyses}

The primary endpoints of the model were life-years gained, quality-adjusted life-years (QALYs), and incremental costeffectiveness ratios (ICERs) for denosumab against the comparators. Univariate sensitivity analyses were performed using efficacy data from the denosumab FREEDOM study for a subpopulation of patients with T-scores of -2.5 or less at the femoral neck, and by extrapolating the treatment duration to 10 years. Multivariate analyses were performed using several variables simultaneously: age at treatment initiation, T-score, and fracture prevalence, comparing denosumab with either no treatment or alendronate (as these were seen as the most likely alternative options).

Using the base-case model, probabilistic sensitivity analyses were conducted using 5,000 simulations. The variables selected and included in this analysis were: denosumab effects, comparator effects, difference in persistence between denosumab and other treatments (DAPS results), and age-dependent costs and utilities for the first year (for hip, vertebral, wrist, and others), age-independent costs, and utilities for the second and subsequent years (hip and vertebral fractures only). Estimates for costs and utilities were sampled from a normal distribution and estimates of hazard ratios for treatment efficacy and the probability of discontinuing treatment were sampled from a log-normal distribution. 
Table 5 Input distributions for probabilistic sensitivity analysis

\begin{tabular}{|c|c|c|c|c|}
\hline \multirow[t]{2}{*}{ Treatment } & \multicolumn{4}{|c|}{$\begin{array}{l}\text { Relative risk of fractures - } \\
\text { treatment versus placebo }\end{array}$} \\
\hline & $\begin{array}{l}\text { Fracture } \\
\text { site }\end{array}$ & Ratio & $\begin{array}{l}\text { Lower } \\
\mathrm{Cl}\end{array}$ & $\begin{array}{l}\text { Upper } \\
\text { CI }\end{array}$ \\
\hline \multirow[t]{4}{*}{ Denosumab } & Hip & 0.60 & 0.37 & 0.97 \\
\hline & Vertebral & 0.32 & 0.26 & 0.41 \\
\hline & Wrist & 0.84 & 0.63 & 1.11 \\
\hline & Other & 0.80 & 0.67 & 0.95 \\
\hline \multirow[t]{4}{*}{ Alendronate } & Hip & 0.62 & 0.40 & 0.96 \\
\hline & Vertebral & 0.56 & 0.46 & 0.67 \\
\hline & Wrist & 0.85 & 0.67 & 1.09 \\
\hline & Other & 0.82 & 0.73 & 0.93 \\
\hline \multirow[t]{4}{*}{ Risedronate } & Hip & 0.74 & 0.59 & 0.93 \\
\hline & Vertebral & 0.64 & 0.52 & 0.78 \\
\hline & Wrist & 0.68 & 0.43 & 1.07 \\
\hline & Other & 0.80 & 0.72 & 0.90 \\
\hline \multirow[t]{4}{*}{ Ibandronate } & Hip & 1.00 & 1.00 & 1.00 \\
\hline & Vertebral & 0.51 & 0.34 & 0.74 \\
\hline & Wrist & 1.00 & 1.00 & 1.00 \\
\hline & Other & 1.00 & 1.00 & 1.00 \\
\hline \multirow[t]{4}{*}{ Strontium ranelate } & Hip & 0.85 & 0.61 & 1.19 \\
\hline & Vertebral & 0.62 & 0.55 & 0.71 \\
\hline & Wrist & 1.00 & 0.74 & 1.36 \\
\hline & Other & 0.86 & 0.74 & 0.99 \\
\hline \multirow{2}{*}{$\begin{array}{l}\text { Fracture type and } \\
\text { duration }\end{array}$} & \multicolumn{4}{|c|}{ Relative standard errors of the mean } \\
\hline & \multicolumn{2}{|l|}{ Cost (\%) } & \multicolumn{2}{|c|}{ Utilities (\%) } \\
\hline Hip fracture, year I & \multicolumn{2}{|l|}{5} & \multicolumn{2}{|l|}{3} \\
\hline Vertebral fracture, year I & \multicolumn{2}{|l|}{13} & \multicolumn{2}{|l|}{6} \\
\hline Wrist fracture, year I & \multicolumn{2}{|l|}{7} & \multicolumn{2}{|l|}{4} \\
\hline Other fracture, year I & \multicolumn{2}{|l|}{13} & \multicolumn{2}{|l|}{6} \\
\hline Hip fracture, year 2+ & \multicolumn{2}{|l|}{10} & \multicolumn{2}{|l|}{7} \\
\hline Vertebral fracture, year $2+$ & \multicolumn{2}{|l|}{10} & \multicolumn{2}{|l|}{6} \\
\hline \multirow{3}{*}{$\begin{array}{l}\text { Proportion of hip } \\
\text { fracture patients going } \\
\text { on to long-term care }\end{array}$} & \multirow{2}{*}{\multicolumn{4}{|c|}{ Relative standard error of the mean }} \\
\hline & & & & \\
\hline & \multicolumn{4}{|l|}{$5 \%$} \\
\hline
\end{tabular}

Abbreviation: $\mathrm{Cl}$, confidence interval.

Input data for the probabilistic sensitivity analyses were taken from the relevant input data sources where possible (Table 5). Denosumab and comparator effect confidence intervals (CIs) were taken from the National Institute for Health and Care Excellence appraisal. ${ }^{41}$ The RR for nonpersistence with denosumab versus other treatments was 0.5 (95\% CI $0.30-1.00) \cdot{ }^{65}$ In the absence of specific data for Spain, standard error proportions of the mean for fracture costs were derived from data from Sweden and were based on the CIs of the whole samples for the respective fracture types. ${ }^{73}$ The standard error proportions of the mean for hip, vertebral, and wrist fractures were $5 \%, 13 \%$, and $7 \%$, respectively. The value for "other" fractures was assumed to be the same as for vertebral fractures, so it was the type with the greatest uncertainty.
Utility multiplier CIs from the study by Peasgood et al ${ }^{63}$ were used to calculate the standard error of the mean (SEM) percentage where applicable. The CIs for hip, vertebral, and wrist fractures were $0.64-0.77,0.46-0.83$, and $0.86-1.00$, respectively, and $0.68-0.96$ for year 2 and onwards for hip fractures. The standard error proportions of the mean for hip, vertebral, and wrist fractures were thus $3 \%, 6 \%$, and $4 \%$, respectively, and $7 \%$ for year 2 and onwards for hip fractures. "Other" fractures were assumed to have the same SEM percentage as vertebral fractures, and the SEM percentage for vertebral fractures in year 2 and onwards were assumed to be the same as for vertebral fractures in year 1. Lastly, in the absence of Spanish data, the SEM percentage for patients with hip fractures going into long-term care was derived from the study by Zethraeus et al ${ }^{74}$ and was 5\% (Table 5).

\section{Results Base case}

The base case in the model assumed patients had been diagnosed with osteoporosis (T-score -2.5 at any site), had a $28 \%$ prevalence of osteoporotic fracture (reported fracture prevalence for patients with T-score $\leq 2.5$ or less in Spain),${ }^{75}$ and had started treatment at the age of 65 years. The comparison between denosumab, bisphosphonates, strontium ranelate, and no treatment in the base-case analysis is presented in Table 6.

Denosumab reduced the risk of fractures compared with either no treatment or the other active interventions, and produced the greatest gains in life-years and QALYs. The total cost for denosumab was, however, higher compared with the other treatment options, with the exception of strontium ranelate. Denosumab dominated strontium ranelate because it was both more effective and less costly. With an annual acquisition cost of $€ 417.34$ for denosumab, ${ }^{58}$ the ICERs for denosumab versus no treatment, alendronate, risedronate, and ibandronate were estimated at $€ 6,823, € 16,294, € 4,895$, and $€ 2,205$ per QALY gained, respectively.

\section{Sensitivity analyses}

The first sensitivity analysis assessed the impact of using efficacy data from the FREEDOM study for the population of patients with a T-score of -2.5 or less at the femoral neck (ie, those with a high risk of fracture, Table 6). This sensitivity analysis showed that, compared with the base case, the ICER estimates improved as denosumab reduced the fracture risk further. Estimated ICERs for denosumab compared with no treatment, alendronate, and risedronate were $€ 3,311$, $€ 9,492$, and $€ 132$ per QALY gained, respectively. As in the 
Table 6 Results of base case and sensitivity analyses

\begin{tabular}{|c|c|c|c|c|c|}
\hline & $\begin{array}{l}\text { Total } \\
\text { costs }(€)\end{array}$ & Life-years & $\begin{array}{l}\text { Life-years } \\
\text { (adjusted) }\end{array}$ & QALYs & $\begin{array}{l}\text { ICER (€/QALY): denosumab } \\
\text { versus comparator }\end{array}$ \\
\hline \multicolumn{6}{|l|}{ Base case } \\
\hline No treatment & 23,122 & 20.803 & 15.156 & 11.899 & 6,823 \\
\hline Alendronate & 22,980 & 20.818 & 15.166 & 11.920 & 16,294 \\
\hline Risedronate & 23,298 & 20.815 & 15.164 & 11.915 & 4,895 \\
\hline Ibandronate & 23,388 & 20.818 & 15.165 & 11.914 & 2,205 \\
\hline Strontium ranelate & 23,890 & 20.815 & 15.163 & 11.913 & Dominant \\
\hline Denosumab & 23,467 & 20.842 & 15.180 & 11.950 & - \\
\hline \multicolumn{6}{|c|}{ Sensitivity analysis (high fracture-risk population [T-score $\leq-2.5$ at femoral neck]) } \\
\hline No treatment & 23,122 & 20.803 & 15.156 & 11.899 & 3,311 \\
\hline Alendronate & 22,981 & 20.818 & 15.166 & 11.920 & 9,492 \\
\hline Risedronate & 23,299 & 20.815 & 15.164 & 11.915 & 132 \\
\hline lbandronate & 23,389 & 20.818 & 15.165 & 11.914 & Dominant \\
\hline Strontium ranelate & 23,891 & 20.815 & 15.163 & 11.913 & Dominant \\
\hline Denosumab & 23,304 & 20.843 & 15.181 & 11.954 & - \\
\hline \multicolumn{6}{|c|}{ Sensitivity analysis (treatment duration extended to 10 years) } \\
\hline No treatment & 23,122 & 20.803 & 15.156 & 11.899 & 3,817 \\
\hline Alendronate & 22,837 & 20.823 & 15.168 & 11.928 & 11,573 \\
\hline Risedronate & 23,307 & 20.819 & 15.166 & 11.921 & 2,077 \\
\hline lbandronate & 23,469 & 20.822 & 15.168 & 11.919 & Dominant \\
\hline Strontium ranelate & 24,155 & 20.818 & 15.166 & 11.918 & Dominant \\
\hline Denosumab & 26,680 & 20.862 & 15.192 & 11.979 & - \\
\hline
\end{tabular}

Abbreviations: ICER, incremental cost-effectiveness ratio; QALY, quality-adjusted life-year.

base-case analysis, denosumab was a dominant treatment alternative to strontium ranelate. It was also shown to be a dominant option compared with ibandronate.

The second sensitivity analysis, in which the treatment duration was extended to 10 years, showed that denosumab was the dominant treatment option compared with ibandronate or strontium ranelate. The cost per QALY gained was $€ 3,817$, €11,573, and $€ 2,077$ compared with no treatment, alendronate, or risedronate, respectively.

The multivariate sensitivity analysis, which simultaneously varied previous fracture status, age, and T-score, showed that, compared with no treatment, denosumab was cost-saving in most cases (Table 7).
For the results comparing denosumab with alendronate, three key variables were identified: age older than 70 years, a T-score of -3.5 or less, and previous fracture. Hence, denosumab appears as dominant for patients fulfilling at least two of these criteria and dominant or cost-effective for most patients fulfilling one of these criteria. Denosumab was probably not cost-effective for patients aged 60 years without a previous fracture and a T-score -3.0 or more (Table 7).

Results of the probabilistic sensitivity analyses using 5,000 simulations on the base case but simultaneously varying the three key variables (age, T-score, and previous fracture status) showed that denosumab had a $57 \%$

Table 7 Incremental cost-effectiveness ratios produced in multivariate sensitivity analysis

\begin{tabular}{|c|c|c|c|c|c|c|c|c|}
\hline \multirow[t]{3}{*}{ T-score } & \multicolumn{4}{|c|}{ No previous fracture } & \multicolumn{4}{|c|}{ Previous fracture } \\
\hline & \multicolumn{4}{|c|}{ Age (years) } & \multicolumn{4}{|l|}{ Age (years) } \\
\hline & 60 & 65 & 70 & 75 & 60 & 65 & 70 & 75 \\
\hline \multicolumn{9}{|c|}{ Denosumab versus no treatment } \\
\hline$\leq-2.5$ & $€ 28,002$ & $€ 15,185$ & $€ 1,629$ & Cost-saving & $€ 2,400$ & Cost-saving & Cost-saving & Cost-saving \\
\hline$\leq-3.0$ & $€ 16,018$ & $€ 5,808$ & Cost-saving & Cost-saving & Cost-saving & Cost-saving & Cost-saving & Cost-saving \\
\hline$\leq-3.5$ & $€ 5,867$ & Cost-saving & Cost-saving & Cost-saving & Cost-saving & Cost-saving & Cost-saving & Cost-saving \\
\hline$\leq-4.0$ & Cost-saving & Cost-saving & Cost-saving & Cost-saving & Cost-saving & Cost-saving & Cost-saving & Cost-saving \\
\hline \multicolumn{9}{|c|}{ Denosumab versus alendronate } \\
\hline$\leq-2.5$ & $€ 42,598$ & $€ 27,50 \mathrm{I}$ & $€ \mid 2,772$ & Cost-saving & $€ 9,890$ & $€ 4,102$ & Cost-saving & Cost-saving \\
\hline$\leq-3.0$ & $€ 28,625$ & $€ \mid 6,487$ & $€ 4,132$ & Cost-saving & $€ 3,932$ & Cost-saving & Cost-saving & Cost-saving \\
\hline$\leq-3.5$ & $€ \mid 6,840$ & $€ 7,038$ & Cost-saving & Cost-saving & Cost-saving & Cost-saving & Cost-saving & Cost-saving \\
\hline$\leq-4.0$ & $€ 7,173$ & Cost-saving & Cost-saving & Cost-saving & Cost-saving & Cost-saving & Cost-saving & Cost-saving \\
\hline
\end{tabular}




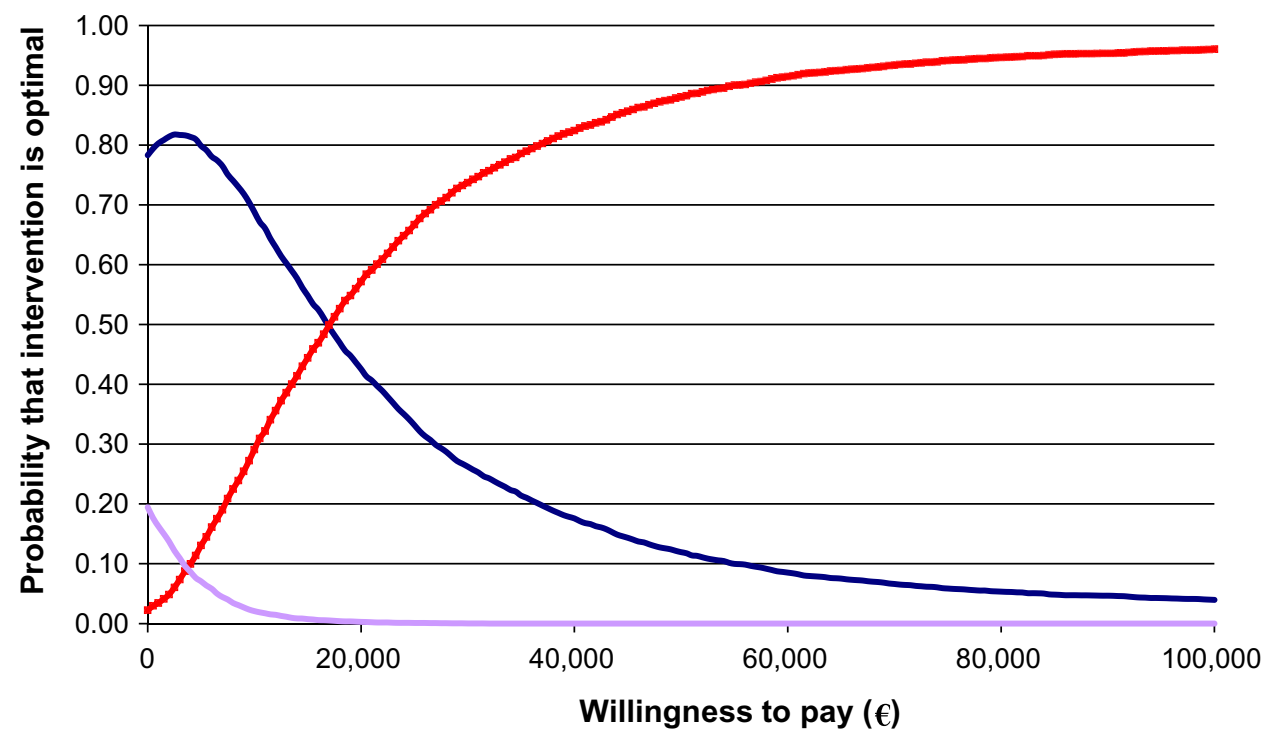

- Alendronate $\longrightarrow$ Denosumab $\_$No treatment

Figure 2 Results of the probabilistic sensitivity analysis showing willingness to pay per quality-adjusted life-year.

probability of being cost-effective compared with alendronate or no treatment at a willingness-to-pay threshold of $€ 20,000$ per QALY gained. This probability was even greater (74\%) if the willingness-to-pay threshold was increased to $€ 30,000$ per QALY gained (Figure 2).

\section{Discussion}

Considerable uncertainty exists around the relative costeffectiveness of treatments in osteoporosis. In Spain, there is no explicitly stated threshold that defines a point at which a treatment is deemed to be cost-effective. However, De Cock et al $^{76}$ suggest that a value between $€ 30,000$ and $€ 45,000$ per QALY gained is reasonable. As with all such thresholds, there are some examples of technologies with costs exceeding $€ 30,000$ per QALY gained that have achieved reimbursement. ${ }^{76,77}$ Nonetheless, using this generally accepted threshold, this study shows that denosumab is a cost-effective treatment option for the prevention of osteoporotic fractures in postmenopausal women in Spain compared with alendronate, risedronate, ibandronate, or no treatment. Denosumab was the dominant treatment option compared with strontium ranelate. These results were demonstrated to be robust in the sensitivity analyses undertaken.

A review of 18 previous studies of bisphosphonate use concluded that these agents were generally cost-effective options for the treatment of PMO, but it was difficult to determine if any one agent was conclusively economically superior to any other. ${ }^{78} \mathrm{~A}$ study of oral bisphosphonates in
Switzerland concluded that they were likely to be cost-saving relative to no treatment, ${ }^{79}$ while a study of tertiary plus secondary prevention measures found bisphosphonates to be cost-effective compared with secondary prevention alone, according to the perspective of the statutory health insurance system in Germany. ${ }^{80}$

One of the most important challenges for decision-makers in the treatment of PMO is identifying the population of patients for whom the treatment is most cost-effective. Based on the results of the multivariate and probabilistic sensitivity analyses conducted in our study, denosumab appears to be cost-effective or cost-saving in most of the scenarios in which it was compared with either alendronate or no treatment. Furthermore, for patients at high risk of fractures (aged over 75 years, with a previous fracture, or a T-score of -3.5 or less), denosumab was cost-saving against both alternatives in most of the scenarios. In additional analyses (results not shown in the paper), where we assumed that there was $100 \%$ persistence with the treatments, an identical pattern was observed compared with no treatment, and denosumab was cost-saving in almost all cases. However, the results for denosumab compared with alendronate differed, with ICERs ranging from $€ 25,046$ to $€ 98,776$ for patients younger than 75 years and with no previous fracture, and from $€ 6,918$ to $€ 35,427$ for patients younger than 75 years with a previous fracture. It is noteworthy that for patients older than 75 years, denosumab still appears to be cost-saving compared with alendronate, both in patients with and without previous fracture. However, such complete persistence, as 
assumed in our model, is rarely seen, so these higher figures should be treated with caution.

Generally, previously published studies have tended to focus on only one or two active comparators per study. For example, a Markov model of the cost utility of risedronate in the UK suggested a cost per QALY gained of $£ 8,625$ per treated woman over a 3 -year time period relative to no treatment. In this case, risedronate was found to be costsaving over an expected lifetime. ${ }^{81}$ Risedronate was also costsaving compared with ibandronate in Italy. ${ }^{82}$ Unfortunately, these approaches are of limited utility to decision-makers, who are generally faced with a much wider range of treatment options to choose from.

There have also been relatively few attempts to examine the cost-effectiveness of osteoporosis treatment in a Spanish setting. A study in Spain showed that the incremental cost per QALY gained for risedronate compared with no treatment in a 70-year-old woman at the "threshold of osteoporosis" (defined as a T-score of -2.5) was $€ 32,515 .{ }^{83} \mathrm{~A}$ similar analysis of similar patients using the Fracture Risk Assessment Tool $\left(\right.$ FRAX $\left.^{\circledR}\right)$ reported an ICER of $€ 105,450$ with bazedoxifene compared with placebo, ${ }^{84}$ and found bazedoxifene to be dominant compared with raloxifene. ${ }^{85} \mathrm{~A}$ comparison of risedronate with alendronate in Spain produced estimates of $€ 43,601$ to $€ 61,064$ per QALY gained for risedronate, and $€ 49,483$ to $€ 88,634$ for alendronate in patients with and without vertebral fractures, respectively. ${ }^{86}$ The authors concluded that risedronate was more cost-effective than alendronate. A large-scale, nine-country study published by Strom et al using 2004 costs showed that, compared with no treatment, the cost-effectiveness of alendronate in Spanish patients with at least one previous vertebral fracture was $€ 13,193$ per QALY gained, and $€ 32,943$ per QALY gained in patients with no previous fracture history. ${ }^{34}$ The results from our analysis show considerably lower cost per QALY estimates for denosumab, which reflects the effect of the superior efficacy and persistence relative to other treatments, although the results of the studies discussed could have been influenced by the use and cost of the branded formulations of bisphosphonates rather than the generic versions which are now available.

The results of our analysis are broadly consistent with other similar attempts to establish the cost-effectiveness of denosumab in various countries. A previous cost-effectiveness analysis of denosumab in Greece showed that the incremental cost per QALY gained ranged between $€ 11,114$ and $€ 24,784$ compared with no treatment, alendronate, ibandronate, risedronate, or strontium ranelate. ${ }^{87}$ A study in Portugal found denosumab to be cost-effective compared with alendronate-cholecalciferol, with an ICER of $€ 14,487 .{ }^{88}$ In the USA, the ICER for denosumab was $\$ 28,300$ per QALY gained compared with generic alendronate, and dominated the other treatment options (risedronate and ibandronate), ${ }^{89}$ depending on the populations considered in the analyses. Similar results have been shown in Belgium, ${ }^{46}$ Canada, ${ }^{90}$ and Sweden ${ }^{33}$ and confirmed by a recent review. ${ }^{45}$ While such similarities in outcomes are not surprising, given the same basic modeling approach in each case, it is notable that the cost-effectiveness estimates, which might be expected to be influenced by local pricing and differences in health care systems, are within the range of values for the ICERs in Spain.

The presented model analyses incorporated persistence with treatment as crucial input for the prediction of cost and outcomes. This is often missing in osteoporosis models and cost-effectiveness models in general. ${ }^{64}$ The base case also included a population with a relatively low fracture risk, rather than patients with established osteoporosis, which was modeled more closely in the sensitivity analysis. Therefore, it is likely that our estimates of the potential benefits and cost-effectiveness of denosumab are conservative. There are also some limitations to our approach. In the absence of Spanish-specific data, we relied on estimates and data from other countries to provide some of the inputs into the model. In light of differences in cultures and health care systems, this undoubtedly increases the uncertainty in our results. However, rigorous testing in the sensitivity analyses of these assumptions confirmed the robustness of the base-case data. The results of the analyses improve with increased treatment duration, with the results from the 10-year treatment duration better than those from 5 years. This could be relevant as the long-term efficacy and safety of denosumab has been confirmed in a recent review ${ }^{91}$ and safety data from 8 years of denosumab use in the extension to the FREEDOM study have recently been presented. ${ }^{92}$

\section{Conclusion}

To our knowledge, this is the first comprehensive attempt to model the cost-effectiveness of the most widely used agents for PMO in Spain. This is an area of increasing interest to both physicians and health care decision-makers, who are seeking to determine the best available treatment options from a large range of available therapies. Previous modeling attempts in Spain have tended to focus on only one or two drugs and as such, have only provided limited guidance for clinical decision-making. The results of our analyses show 
that denosumab is a cost-effective intervention for fracture prevention in postmenopausal women in Spain compared with alendronate, risedronate, ibandronate, or no treatment, and is a dominant treatment option compared with strontium ranelate. Additionally, for those patients at the highest risk of fractures (aged over 75 years, with a previous fracture, or a T-score of -3.5 or less), denosumab was generally costsaving compared with either alendronate or no treatment in most of the scenarios.

\section{Acknowledgment}

The authors sincerely appreciate the work done by i3 Innovus on developing the original model.

\section{Disclosure}

The preliminary results of this study were presented at the International Society of Pharmacoeconomics and Outcomes Research 14th Annual European Congress, November 5-8, 2011, Madrid, Spain. This work was funded by Amgen SA Barcelona, Spain, and GSK. JD and LK received funding for their involvement in this study. FSV and ML are employees of and have stock ownership in Amgen Inc. Writing assistance was provided by Keith Evans of InScience Communications, Springer Healthcare, and Oxford PharmaGenesis ${ }^{\mathrm{TM}}$, which was funded by Amgen SA and GSK. The authors report no other conflicts of interest in this work.

\section{References}

1. Boyle IT. Bones for the future. Acta Paediatr Scand Suppl. 1991; 80(373):58-65.

2. McClung MR. The menopause and HRT. Prevention and management of osteoporosis. Best Pract Res Clin Endocrinol Metab. 2003; 17(1):53-71.

3. McNamara LM. Perspective on post-menopausal osteoporosis: establishing an interdisciplinary understanding of the sequence of events from the molecular level to whole bone fractures. $J R$ Soc Interface. 2010;7(44):353-372.

4. Bianchi ML, Orsini MR, Saraifoger S, Ortolani S, Radaelli G, Betti S. Quality of life in post-menopausal osteoporosis. Health Qual Life Outcomes. 2005;3:78.

5. Marquis P, Cialdella P, De la Loge C. Development and validation of a specific quality of life module in post-menopausal women with osteoporosis: the QUALIOST. Qual Life Res. 2001;10(6):555-566.

6. Calvo E, Morcillo D, Foruria AM, Redondo-Santamaria E, Osorio-Picorne F, Caeiro JR; GEIOS-SECOT Outpatient Osteoporotic Fracture Study Group. Nondisplaced proximal humeral fractures: high incidence among outpatient-treated osteoporotic fractures and severe impact on upper extremity function and patient subjective health perception. $J$ Shoulder Elbow Surg. 2011;20(5):795-801.

7. Sanfelix-Genoves J, Hurtado I, Sanfelix-Gimeno G, Reig-Molla B, Peiro S. Impact of osteoporosis and vertebral fractures on quality-of-life. A population-based study in Valencia, Spain (the FRAVO study). Health Qual Life Outcomes. 2011;9:20.

8. Adkins J, Kassianos G. Ibandronate - a convenient and effective treatment option for the management of post-menopausal osteoporosis. Drugs Context. 2008;4(2):121-134.
9. Aka N, Balkan E, Zeynep Tuzcular Vural E, Yazicioglu E. The risk factors in postmenopausal osteoporosis. Marmara Medical Journal. 2000;13(4):219-222.

10. Diaz Curiel M, Garcia JJ, Carrasco JL, et al. [Prevalence of osteoporosis assessed by densitometry in the Spanish female population]. Med Clin (Barc). 2001;116(3):86-88. Spanish.

11. Cipriani C, Romagnoli E, Minisola S. Pharmacological treatment of osteoporosis - old and new drugs. Eur Musculoskelet Rev. 2011;6(2): 83-87.

12. Cole Z, Dennison E, Cooper C. Update on the treatment of postmenopausal osteoporosis. Br Med Bull. 2008;86(1):129-143.

13. Sammartino A, Cirillo D, Mandato VD, Di Carlo C, Nappi C. Osteoporosis and cardiovascular disease: benefit-risk of hormone replacement therapy. J Endocrinol Invest. 2005;28(10 Suppl):80-84.

14. Viktoria Stein K, Dorner T, Lawrence K, Kunze M, Rieder A. [Economic concepts for measuring the costs of illness of osteoporosis: an international comparison]. Wien Med Wochenschr. 2009;159(9-10): 253-261. German

15. Bouza C, Lopez T, Palma M, Amate JM. Hospitalised osteoporotic vertebral fractures in Spain: analysis of the National Hospital Discharge Registry. Osteoporos Int. 2007;18(5):649-657.

16. Pueyo MJ, Larrosa M, Suris X, Garcia-Ruiz AJ. Cost-utility and budget impact analysis of primary prevention with alendronate of osteoporotic hip fractures in Catalonia. Reumatol Clin. 2012;8(3):128-134.

17. Rizzoli R. Bisphosphonates for post-menopausal osteoporosis: are they all the same? QJM. 2011;104(4):281-300.

18. Cavalli L, Brandi ML. Targeted approaches in the treatment of osteoporosis: differential mechanism of action of denosumab and clinical utility. Ther Clin Risk Manag. 2012;8:253-266.

19. Adami S, Felsenberg D, Christiansen C, et al. Efficacy and safety of ibandronate given by intravenous injection once every 3 months. Bone. 2004;34(5):881-889.

20. Kremer R. New targets for osteoporosis. Presented at the International Symposium on Multidisciplinary Approaches to Modern Therapeutics Joining Forces for a Healthier Tomorrow, May 24-27, 2011, Montreal, QC, Canada.

21. Boyle WJ, Simonet WS, Lacey DL. Osteoclast differentiation and activation. Nature. 2003;423(6937):337-342.

22. Pola E, Colangelo D, Fusco A, et al. Efficacy of the anabolic therapies in severe osteoporosis: experience of a team of endocrinologists and orthopaedic surgeons and clinical results. J Orthopaed Traumatol. 2011;12 Suppl 1:S1-S22.

23. Przedlacki J. Strontium ranelate in post-menopausal osteoporosis. Endokrynol Pol. 2011;62(1):65-72.

24. Corrado A, Quarta L, Errico S, Cantatore FP. Successful treatment of avascular bone necrosis of the knee with neridronate: a case report. Rheumatol Int. 2007;27(9):891-893.

25. Cotte FE, Cortet B, Lafuma A, et al. A model of the public health impact of improved treatment persistence in post-menopausal osteoporosis in France. Joint Bone Spine. 2008;75(2):201-208.

26. Cotte FE, De Pouvourville G. Cost of non-persistence with oral bisphosphonates in post-menopausal osteoporosis treatment in France. BMC Health Serv Res. 2011;11:151

27. Payer J, Cierny D, Killinger Z, Sulkova I, Behuliak M, Celec P. Preferences of patients with post-menopausal osteoporosis treated with bisphosphonates - the VIVA II study. J Int Med Res. 2009;37(4): $1225-1229$.

28. Sicras-Mainar A, Navarro-Artieda R, Gutierrez L, Sorio F, Intorcia M. Persistence to postmenopausal osteoporosis (PMO) treatments in a region of Spain. Value Health. 2010;13(7):A380.

29. Karamustafa F, Celebi N. Bisphosphonates and alendronate. FABAD J Pharm Sci. 2006;31(1):31-42.

30. Perazella MA, Markowitz GS. Bisphosphonate nephrotoxicity. Kidney Int. 2008;74(11):1385-1393.

31. Borromeo GL, Brand C, Clement JG, et al. Is bisphosphonate therapy for benign bone disease associated with impaired dental healing? A case-controlled study. BMC Musculoskelet Disord. 2011;12:71. 
32. Perez Edo L, Alonso Ruiz A, Roig Vilaseca D, et al. [Update of the consensus statement of the Spanish Society of Rheumatology on osteoporosis]. Reumatol Clin. 2011;7(6):357-379. Spanish.

33. Jonsson B, Strom O, Eisman JA, et al. Cost-effectiveness of denosumab for the treatment of postmenopausal osteoporosis. Osteoporos Int. 2011;22(3):967-982.

34. Strom O, Borgstrom F, Sen SS, et al. Cost-effectiveness of alendronate in the treatment of postmenopausal women in 9 European countries an economic evaluation based on the Fracture Intervention Trial. Osteoporos Int. 2007;18(8):1047-1061.

35. Kanis JA, Johnell O, Oden A, Jonsson B, Dawson A, Dere W. Risk of hip fracture derived from relative risks: an analysis applied to the population of Sweden. Osteoporos Int. 2000;11(2):120-127.

36. De Laet CE, van Hout BA, Burger H, Hofman A, Pols HA. Bone density and risk of hip fracture in men and women: cross sectional analysis. BMJ. 1997;315(7102):221-225.

37. Johnell O, Kanis JA, Oden A, et al. Predictive value of BMD for hip and other fractures. J Bone Miner Res. 2005;20(7):1185-1194.

38. Klotzbuecher CM, Ross PD, Landsman PB, Abbott TA 3rd, Berger M. Patients with prior fractures have an increased risk of future fractures: a summary of the literature and statistical synthesis. J Bone Miner Res. 2000;15(4):721-739.

39. Simon JA, Recknor C, Moffett AH Jr, et al. Impact of denosumab on the peripheral skeleton of postmenopausal women with osteoporosis: bone density, mass, and strength of the radius, and wrist fracture. Menopause. 2013;20(2):130-137.

40. Cummings SR, San Martin J, McClung MR, et al. Denosumab for prevention of fractures in postmenopausal women with osteoporosis. N Engl J Med. 2009;361(8):756-765.

41. National Collaborating Centre for Nursing and Supportive Care. Systematic reviews of clinical effectiveness prepared for the guideline 'Osteoporosis: assessment of fracture risk and the prevention of osteoporotic fractures in individuals at high risk'. London, UK: National Institute for Health and Clinical Excellence; 2008. Available from: https://www.nice.org.uk/guidance/cg146/documents/osteoporosisevidence-reviews2. Accessed January 16, 2015.

42. Boonen S, Adachi JD, Man Z, et al. Treatment with denosumab reduces the incidence of new vertebral and hip fractures in postmenopausal women at high risk. J Clin Endocrinol Metab. 2011;96(6): 1727-1736.

43. McClung M, Boonen S, Torring O, et al. Effect of denosumab treatment on the risk of fractures in subgroups of women with postmenopausal osteoporosis. J Bone Miner Res. 2012;27(1):211-218.

44. Hemminki A, Dmitriev I, Liu B, Desmond RA, Alemany R, Curiel DT. Targeting oncolytic adenoviral agents to the epidermal growth factor pathway with a secretory fusion molecule. Cancer Res. 2001;61(17): 6377-6381.

45. Hiligsmann M, Boonen A, Dirksen CD, Ben Sedrine W, Reginster JY. Cost-effectiveness of denosumab in the treatment of postmenopausal osteoporotic women. Expert Rev Pharmacoecon Outcomes Res. 2013;13(1):19-28.

46. Hiligsmann M, Reginster JY. Cost effectiveness of denosumab compared with oral bisphosphonates in the treatment of post-menopausal osteoporotic women in Belgium. Pharmacoeconomics. 2011;29(10): 895-911.

47. Alvarez-Nebreda ML, Jimenez AB, Rodriguez P, Serra JA. Epidemiology of hip fracture in the elderly in Spain. Bone. 2008;42(2):278-285.

48. Ismail AA, Pye SR, Cockerill WC, et al. Incidence of limb fracture across Europe: results from the European Prospective Osteoporosis Study (EPOS). Osteoporos Int. 2002;13(7):565-571.

49. Marin F, Gonzalez-Macias J, Moya R, et al. [Fragility non-spinal fractures in a cohort of 5,201 women aged 65 years and older during a 3-year follow-up]. Med Clin (Barc). 2006;127(11):401-404. Spanish.

50. Naves Diaz M, Diaz Lopez JB, Gomez Alonso C, Altadill Arregui A, Rodriguez Rebollar A, Cannata Andia JB. [Study of incidence of osteoporotic fractures in a cohort of individuals older than 50 years from Asturias, Spain, after a 6 year follow-up period]. Med Clin (Barc). 2000;115(17):650-653. Spanish.
51. EPOS Study Group. Incidence of vertebral fracture in Europe: results from the European Prospective Osteoporosis Study (EPOS). $J$ Bone Miner Res. 2002;17(4):716-724.

52. Kanis JA, Oden A, Johnell O, De Laet C, Jonsson B. Excess mortality after hospitalisation for vertebral fracture. Osteoporos Int. 2004;15(2): $108-112$.

53. Kanis JA, Oden A, Johnell O, De Laet C, Jonsson B, Oglesby AK. The components of excess mortality after hip fracture. Bone. 2003;32(5): 468-473.

54. Instituto Nacional de Estadistica. [Population figures and demographic censuses]. 2011. Available from: http://www.ine.es/inebmenu/ mnu_cifraspob.htm\#6. Accessed January 16, 2015. Spanish.

55. Barrett JA, Baron JA, Beach ML. Mortality and pulmonary embolism after fracture in the elderly. Osteoporos Int. 2003;14(11):889-894.

56. Parker MJ, Anand JK. What is the true mortality of hip fractures? Public Health. 1991;105(6):443-446.

57. Gisbert R, Brosa M. Spanish Health Costs Database 2011. Available from http://www.oblikue.com/bddcostes/. Accessed January 16, 2015.

58. Consejo General de Colegios Oficiales de Farmacéuticos. Portalfarma, 2014. Available from http://www.portalfarma.com/inicio/botplus20/ Paginas/Bot-PLUS-2-0.aspx. Accessed January 16, 2015.

59. Baztan JJ, Caceres LA, Llanque JL, Gavidia JJ, Ruiperez I. Predictors of functional recovery in older hospitalized adults. J Am Geriatr Soc. 2012;60(1):187-189.

60. De la Torre García M, Rodríguez Pérez JC, Moreno Moreu N, Jacinto RL, Hernández Santana A, Deive Maggiolo JC. [Economic impact study of the hip fractures in our midst]. Trauma. 2012;23:1. Spanish.

61. Lopez-Bastida J, Oliva J, Antonanzas F, et al. Spanish recommendations on economic evaluation of health technologies. Eur J Health Econ. 2010;11(5):513-520.

62. Kanis JA, Johnell O, Oden A, et al. The risk and burden of vertebral fractures in Sweden. Osteoporos Int. 2004;15(1):20-26.

63. Peasgood T, Herrmann K, Kanis JA, Brazier JE. An updated systematic review of health state utility values for osteoporosis related conditions. Osteoporos Int. 2009;20(6):853-868.

64. Kanis JA, Cooper C, Hiligsmann M, Rabenda V, Reginster JY, Rizzoli R. Partial adherence: a new perspective on health economic assessment in osteoporosis. Osteoporos Int. 2011;22(10):2565-2573.

65. Freemantle N, Satram-Hoang S, Tang ET, et al. Final results of the DAPS (Denosumab Adherence Preference Satisfaction) study: a 24-month, randomized, crossover comparison with alendronate in postmenopausal women. Osteoporos Int. 2012;23(1):317-326.

66. Landfeldt E, Strom O, Robbins S, Borgstrom F. Adherence to treatment of primary osteoporosis and its association to fractures - the Swedish Adherence Register Analysis (SARA). Osteoporos Int. 2012;23(2): 433-443.

67. Caulin F, Kanis JA, Johnell O, Oden A. Optimal age for preventing osteoporosis after menopause depends on effects of stopping treatment. Bone. 2002;30(5):754-758.

68. Jonsson B, Kanis J, Dawson A, Oden A, Johnell O. Effect and offset of effect of treatments for hip fracture on health outcomes. Osteoporos Int. 1999;10(3):193-199.

69. Harada A. [Absolute risk for fracture and WHO guideline. Economic analysis of pharmacotherapy for osteoporosis]. Clin Calcium. 2007; 17(7):1029-1034. Japanese.

70. Kanis JA, Borgstrom F, Zethraeus N, Johnell O, Oden A, Jonsson B. Intervention thresholds for osteoporosis in the UK. Bone. 2005;36(1): $22-32$.

71. Mullins CD, Ohsfeldt RL. Modeling the annual costs of postmenopausal prevention therapy: raloxifene, alendronate, or estrogen-progestin therapy. J Manag Care Pharm. 2003;9(2):150-158.

72. Strom O, Borgstrom F, Kanis JA, Jonsson B. Incorporating adherence into health economic modelling of osteoporosis. Osteoporos Int. 2009;20(1):23-34.

73. Borgstrom F, Zethraeus N, Johnell O, et al. Costs and quality of life associated with osteoporosis-related fractures in Sweden. Osteoporos Int. 2006;17(5):637-650. 
74. Zethraeus N, Strom CM, Borgstrom A. What is the risk of institutionalization after hip fracture? Osteoporosis Int. 2006;17 Suppl 2:S60.

75. Sanfelix-Genoves J, Reig-Molla B, Sanfelix-Gimeno G, et al. The population-based prevalence of osteoporotic vertebral fracture and densitometric osteoporosis in postmenopausal women over 50 in Valencia, Spain (the FRAVO study). Bone. 2010;47(3):610-616.

76. De Cock E, Miravitlles M, Ramón González-Juanatey J, Ramón Azanza-Perea J. [Threshold of cost per life year gained to recommend the adoption of health technologies in Spain: evidence from a review of the literature]. Pharmacoeconomics - Spanish Research Articles. 2007;4(3):97-107. Spanish.

77. Sacristan JA, Oliva J, Del Llano J, Prieto L, Pinto JL. [What is an efficient health technology in Spain?]. Gac Sanit. 2002;16(4):334-343. Spanish.

78. Ousterhout MM, Blaser DA, Gagnon J. Cost-effectiveness comparative analysis of bisphosphonates for the treatment of post-menopausal osteoporosis. Presented at the 16th Annual International Meeting of the International Society of Pharmacoeconomics and Outcomes Research, May 21-25, 2011, Baltimore, MD, USA.

79. Lippuner K, Pollock RF, Smith-Palmer J, Meury T, Valentine WJ. A review of the cost effectiveness of bisphosphonates in the treatment of post-menopausal osteoporosis in Switzerland. Appl Health Econ Health Policy. 2011;9(6):403-417.

80. Mueller D, Gandjour A. Cost effectiveness of secondary vs tertiary prevention for post-menopausal osteoporosis. Appl Health Econ Health Policy. 2011;9(4):259-273.

81. Iglesias CP, Torgerson DJ, Bearne A, Bose U. The cost utility of bisphosphonate treatment in established osteoporosis. QJM. 2002;95(5): 305-311.

82. Maggi S, Pasquale M, Bouin O. Modeled cost-effectiveness of risedronate versus ibandronate: the case of Italy. J Bone Miner Res. 2008; 23 Suppl:S213.

83. Borgstrom F, Carlsson A, Sintonen H, et al. The cost-effectiveness of risedronate in the treatment of osteoporosis: an international perspective. Osteoporos Int. 2006;17(7):996-1007.

84. Borgstrom F, Strom O, Kleman M, et al. Cost-effectiveness of bazedoxifene incorporating the FRAX ${ }^{\circledR}$ algorithm in a European perspective. Osteoporos Int. 2011;22(3):955-965.

85. Kim K, Svedbom A, Luo X, Sutradhar S, Kanis JA. Comparative cost-effectiveness of bazedoxifene and raloxifene in the treatment of postmenopausal osteoporosis in Europe, using the FRAX algorithm. Osteoporos Int. 2014;25(1):325-337.
86. Hart WM, Rubio-Terres C, Burrell A, Aristegui I, Escobar-Jimenez F. [Pharmacoeconomic analysis of the treatment of postmenopausal osteoporosis with risedronate or alendronate]. Revista Espanola de Enfermedades Metabolicas Oseas. 2002;11(3):97-104. Spanish.

87. Athanasakis K, Karampli E, Hollandezos M, et al. A cost-effectiveness analysis of denosumab for the treatment of post-menopausal osteoporosis in Greece. Value Health. 2011;14(7):A308.

88. Cristino J, Canhao H, Perelman J, Santos C, Pereira J. Cost-utility analysis of denosumab versus standard care in the treatment of post-menopausal osteoporosis in Portugal. Poster presented at the 16th Annual International Meeting of the International Society for Pharmacoeconomics and Outcomes Research, May 21-25, 2011, Baltimore, MD, USA.

89. Parthan A, Deflin MM, Yurgin N, Huang J, Taylor DC. Cost-effectiveness of denosumab versus oral bisphosphonates in the United States for post-menopausal osteoporosis (PMO). Abstract PMS26 presented at the 17th Annual International Meeting of the International Society for Pharmacoeconomics and Outcomes Research, June 2-6, 2012, Washington, DC, USA.

90. Chau D, Becker DL, Coombes ME, Ioannidis G, Adachi JD, Goeree R. Cost-effectiveness of denosumab in the treatment of postmenopausal osteoporosis in Canada. J Med Econ. 2012;15 Suppl 1:3-14.

91. Anastasilakis AD, Toulis KA, Polyzos SA, Anastasilakis CD, Makras P. Long-term treatment of osteoporosis: safety and efficacy appraisal of denosumab. Ther Clin Risk Manag. 2012;8:295-306.

92. Papapoulos S, Lippuner K, Roux C, et al. Eight years of denosumab treatment in postmenopausal women with osteoporosis: results from the first five years of the FREEDOM extension. $J$ Osteoporosis Int. 2014;25(2):46-47.

93. National Insitute of Health and Clinical Excellence. Alendronate, etidronate, risedronate, raloxifene and strontium ranelate for the primary prevention of osteoporotic fragility fractures in postmenopausal women (amended), 2011. Available from: http://www.nice.org.uk/guidance/ ta161. Accessed January 16, 2015.

94. Inderjeeth CA, Foo AC, Lai MM, Glendenning P. Efficacy and safety of pharmacological agents in managing osteoporosis in the old old: review of the evidence. Bone. 2009;44(5):744-751.

95. Imaz Iglesia I. Análisis coste-utilidad de los tratamientos farmacológicos para la prevención de fracturas en mujeres con osteoporosis en España. IPE 63/2010. Agencia de Evaluación de Tecnologías Sanitarias. Instituto de Salud Carlos III. Madrid, 2010.
ClinicoEconomics and Outcomes Research

\section{Publish your work in this journal}

ClinicoEconomics \& Outcomes Research is an international, peerreviewed open-access journal focusing on Health Technology Assessment, Pharmacoeconomics and Outcomes Research in the areas of diagnosis, medical devices, and clinical, surgical and pharmacological intervention. The economic impact of health policy and health systems

\section{Dovepress}

organization also constitute important areas of coverage. The manuscript management system is completely online and includes a very quick and fair peer-review system, which is all easy to use. Visit http://www.dovepress.com/testimonials.php to read real quotes from published authors. 